University of Nebraska - Lincoln

DigitalCommons@University of Nebraska - Lincoln

Faculty Publications, Department of Psychology

Psychology, Department of

1975

Societal complexity and moral development: A Kenyan study.

Carolyn P. Edwards

University of Nebraska-Lincoln, cedwards1@unl.edu

Follow this and additional works at: https://digitalcommons.unl.edu/psychfacpub

Part of the Developmental Psychology Commons, and the Social and Cultural Anthropology Commons

Edwards, Carolyn P., "Societal complexity and moral development: A Kenyan study." (1975). Faculty Publications, Department of Psychology. 604.

https://digitalcommons.unl.edu/psychfacpub/604

This Article is brought to you for free and open access by the Psychology, Department of at DigitalCommons@University of Nebraska - Lincoln. It has been accepted for inclusion in Faculty Publications, Department of Psychology by an authorized administrator of DigitalCommons@University of Nebraska - Lincoln. 


\title{
Societal Complexity and Moral Development: A Kenyan Study
}

\author{
Carolyn P. Edwards
}

At the turn of the century, in the wave of evolutionary speculation that followed the dissemination of Darwin's ideas, several influential Western philosophers attempted to link the evolution of human society to the progress of morals. Authors such as Herbert Spencer (1899), L. T. Hobhouse (1906), and John Dewey and James Tufts (1908) argued that forms of ethical thought can be ordered along an evolutionary dimension from simple to complex. They suggested that the human species has ascended this scale as it has progressed from the level of social organization of the most prim-

Carolyn P. Edwards is assistant professor of psychology at Vassar College, Poughkeepsie, New York.

This paper is based upon research in Kenya with adults and adolescents from a variety of cultural traditions. The research was conducted during $1972-$ 1973 at the Child Development Research Unit (John W. M. Whiting, director) at the University of Nairobi and was supported by grants from the National Institute of Mental Health (MH1096-18) and the Carnegie Corporation.

This paper was first presented at the Annual Meeting of the Society for CrossCultural Research, April, 1975, in Chicago, Illinois. I would like to thank Beatrice and John Whiting, who gave much help and support throughout the research leading to this paper. 
itive hunting and gathering societies to the level of the most complex, large-scale nations. Western Europe represented the pinnacle of both ethical development and societal evolution.

For the last several decades these arguments have generally met with disapproval in the social sciences. Anthropologists have repudiated what they perceive to be nineteenth-century whitesupremacist attitudes toward foreign cultures. They prefer to adhere to the doctrine of cultural relativity, according to which there is no scientific basis for judging the value systems of different cultures in terms of ethical superiority and inferiority. A system of norms represents the attempt by a people to solve the life and death problems of their existence and as such it has validity for that group. Because there exist no objective means to measure and scale the problems faced by different cultural groups, there exist no standards by which to judge one people's solution as ethically superior to another's.

Until recently most developmental psychologists have held a theory of childhood socialization which supports the anthropologists' position (reviewed by Kohlberg 1971). They have described the process of acquiring moral rules as one of internalization of cultural values. Their theory proposes that as children grow older, they absorb or "internalize" the values around them and hence display more and more fully the standards of adult society. Socialization is the process by which the parent generation transmits its values to the younger generation. A corollary to the theory is that the moral behavior of individual children cannot be compared except with reference to the value systems of their families. From this standpoint, the "more moral" child is simply the one who conforms more thoroughly to parental values (for a full discussion of the internalization of moral rules, see Aronfreed 1968). This theory grows out of the Freudian and behaviorist traditions in psychology.

An alternative and opposing perspective emerges from the cognitive-developmental school. His research growing out of an early work of Jean Piaget (1932), Lawrence Kohlberg has disputed the view of moralization as internalization of cultural values and instead presented a stage theory of moral development (1963, 1969, 1971). Kohlberg's theory represents a synthesis of ideas from philosophy and psychology. Its major theoretical forefathers are James Mark Baldwin, L. T. Hobhouse, George Herbert Mead, Dewey and 
Tufts, and Piaget. From Baldwin (1902) came the conception of the stages (especially the description of the first two stages) and a theory that growth occurs through a process of continual small adjustments-"assimilations" and "accomodations"-which tend toward a state of homeostasis. From Hobhouse (1906) came the evolutionary doctrine that links societal evolution to moral progress. Mead (1934) provided the idea that increased capacity for taking the perspective of others ("role-taking") lies behind moral development. Dewey and Tufts (1908) proposed a three-tiered system of "pre-customary, customary, and reflective" levels of morality, which are directly analogous to Kohlberg's three levels_- "preconventional, conventional, and principled"-to be described below. Finally, from Piaget (1932) came a theory of justice as social reciprocity and the method of the clinical interview. Hypothetical moral dilemmas, the heart of Kohlberg's method, represent an elaboration of the method of questioning which Piaget used with young children.

Kohlberg's theory is based on a system of six moral judgment stages, which are secondarily grouped into three levels. A summary of this system is presented in table 1. The preconventional level, which includes stages 1 and 2, is the level at which one would expect to find most children and some adults in any society. In contrast, the conventional and principled levels contain the four stages (stages 3 to 6) more likely to be seen in adults than in children. Although no statistical estimates exist for the frequency of the four upper stages in any adult population, even the United States, it is likely that stage 3 is most common, followed by stage 4 , and that stages 5 and 6 are exceedingly infrequent except among highly educated, elite groups.

In Kohlberg's view, moral judgment develops in an invariant order through the sequence of stages. That is, insofar as the child's moral reasoning changes, it is transformed from a lower stage to a higher stage-without skipping or bypassing any intermediate stages. A stage is a network of basic organizing principles for conducting moral thinking. Its structure provides a framework for all aspects of the person's moral reasoning. The judgments found at each stage are more complex and differentiated than at the stage before it; they involve what are not only logically but also intuitively more elaborate modes of decision making. Individual differences in moral development appear in the rate at which children progress 
TABLE 1

Definition of the Moral Stages

\section{Preconventional Level}

At this level the child is responsive to cultural rules and labels of good and bad, right or wrong, but interprets these labels in terms of either the physical or the hedonistic consequences of action (punishment, reward, exchange of favors), or in terms of the physical power of those who enunciate the rules and labels. The level is divided into the following two stages:

Stage 1: The punishment and obedience orientation. The physical consequences of action determine its goodness or badness regardless of the human meaning or value of these consequences. Avoidance of punishment and unquestioning deference to power are valued in their own right, not in terms of respect for an underlying moral order supported by punishment and authority (the latter being stage 4).

Stage 2: The instrumental relativist orientation. Right action consists of what instrumentally satisfies one's own needs and occasionally the needs of others. Human relations are viewed in terms like those of the market place. Elements of fairness, of reciprocity, and of equal sharing are present, but they are always interpreted in a physical pragmatic way. Reciprocity is a matter of "you scratch my back and I'll scratch yours," not of loyalty, gratitude, or justice.

\section{Conventional Level}

At this level, maintaining the expectations of the individual's family, group, or nation is perceived as valuable in its own right, regardless of immediate and obvious consequences. The attitude is not only one of conformity to personal expectations and social order, but of loyalty to it, of actively maintaining, supporting, and justifying the order, and of identifying with the persons or group involved in it. At this level, there are the following two stages:

Stage 3: The interpersonal concordance or "good boy-nice girl" orientation. Good behavior is what pleases or helps others and is approved by them. There is much conformity to stereotypical images of what is majority or "natural" behavior. Behavior is frequently judged by intention-"he means well" becomes important for the first time. One earns approval by being "nice."

Stage 4: The "law and order" orientation. There is orientation toward authority, fixed rules, and the maintenance of the social order. Right behavior consists of doing one's duty, showing respect for authority, and maintaining the given social order for it's own sake.

\section{Postconventional, Autonomous, or Principled Level}

At this level, there is a clear effort to define moral values and principles that have validity and application apart from the authority of the groups or persons holding these principles, and apart from the individual's own identification with these groups. This level again has two stages:

Stage 5. The social-contract legalistic orientation, generally with utilitarian overtones. Right action tends to be defined in terms of general individual rights, and standards that have been critically examined and agreed upon by the whole society. There is a clear awareness of the relativism of personal values and opinions and a corresponding emphasis upon procedural rules for reaching consensus. Aside from what is constitutionally and democratically agreed upon, the right is a matter of personal "values" and "opinion." The result is an emphasis 
upon the "legal point of view," but with an emphasis upon the possibility of changing law in terms of rational considerations of social utility (rather than freezing it in terms of stage 4 "law and order"). Outside the legal realm, free agreement and contract is the binding element of obligation. This is the "official" morality of the American government and constitution.

Stage 6: The universal ethical principle orientation. Right is defined by the decision of conscience in accord with self-chosen ethical principles appealing to logical comprehensiveness, universality, and consistency. These principles are abstract and ethical (the Golden Rule, the categorical imperative); they are not concrete moral rules like the Ten Commandments. At heart, these are universal principles of justice, of the reciprocity and equality of human rights, and of respect for the dignity of human beings as individual persons.

(From Kohlberg 1971:164-165)

as well as in their terminal points of development; that is, not all children advance equally quickly or ultimately as far as others. Little is known about how much development may, or typically does, occur during the adult years of life.

A signal feature of Kohlberg's theory is his assertion that the system of stages is culturally universal (Kohlberg 1969). This claim is probably valid with respect to the process or sequence of development. Kohlberg proposes that in every cultural setting all of the children can be expected to display the same fixed order of stages as they grow older. Cross-sectional data from five societies (Kohlberg 1969) as well as longitudinal data from Turkey (Turiel, Kohlberg, and Edwards n.d.) support this hypothesis. Nevertheless, while some of the stages have definitely been recorded in the interviews of children from diverse cultures, not all of the stages have been so found. Statements representative of the higher moral stages seem to be absent from the interviews of children raised in semiliterate, relatively isolated peasant villages in Turkey (Turiel, Kohlberg, and Edwards n.d.), British Honduras (Gorsuch and Barnes 1973), and the Bahamas (White 1975). In contrast, higher stage reasoning has been scored in the protocols of urban school children from Turkey (Turiel, Kohlberg, and Edwards n.d.), Taiwan, Mexico, and the United States (Kohlberg 1969), as well as children from England (Simpson and Graham n.d.). Hence, only Kohlberg's lower moral stages have been proved to be universal to the cultures thus far sampled (and these include no hunter-gatherer groups). The higher stages appear to be culture-specific, just the opposite of culturally universal. Therefore, while the sequence of 
stages in children's development may be invariant from culture to culture, only the first several stages in the system likely constitute universal modes of reasoning.

Kohlberg explains the lack of the higher stages in the peasant samples through what he calls "a mild doctrine of social evolutionism, such as was elaborated in the classic work of Hobhouse" (Kohlberg 1971:178). Thus, Kohlberg reintroduces the evolutionary doctrine previously discounted. In Kohlberg's view, all environments are not expected to promote the development of moral judgment equally. Rather, for different cultural settings, there will be different terminal points of development. In other words, the typical or modal child in some cultures will develop farther than the modal child in other cultures because their social environments affect their processes of growth somewhat differently. The critical variable that determines the terminal point for the children's development within a particular cultural setting is the "complexity" of its social and political organization (Kohlberg 1971). The more complex the institutional arrangements of a particular society, the more likely it is that higher stage subjects will be found within that society.

The critical idea here is that the end point of the development of moral judgment is related to a structural feature of the social environment, namely, the complexity of institutional arrangements. Can this be true? If so, the evolutionary implications that Kohlberg stresses might not be the finding of central importance. More significant, the moral development evidence suggests one way in which cross-cultural differnces in cognitive functioning might be related to variation in the pattern of the everyday lives of human beings. The sphere of everyday life of interest would include interpersonal disagreements and conflicts of claims. The nature of such problems might differ systematically among different types of societies, and therefore individual modes of conceptualizing moral issues might tend to vary also. Several anthropologists and psychologists (e.g. Bruner, Oliver, and Greenfield 1966, Horton 1967, Gladwin 1970, Cole et al. 1971) have recently debated whether scientific modes of reasoning vary from society to society in accordance with differences in the kinds of cognitive tasks typically encountered by people in those societies. The cross-cultural research on moral judgment raises a parallel question and suggests that certain of the 
mental processes involved in moral judging might correspond to the requirements of social life in different parts of the world.

This paper suggests reasons why the higher stages of moral judgment are not culturally universal. If certain moral decision modes are found only in the protocols of subjects from the developed countries or from urban areas in the developing countries, this suggests that such modes are relevant to problems salient in these "complex" social contexts but subordinate in other types of cultural settings. To be specific, the evidence suggests that stages 1 to 3 are definitely present among adults whose frame of reference is a traditional and isolated peasant village as well as among adults from more modern settings. In contrast, the cross-cultural research with adult subjects, including the findings reported below, indicates that reasoning that is characteristic of stages 4,5 , and 6 is limited to educated subjects whose frame of reference is a complex society such as a modern national state. If so, a boundary exists between stages 3 and 4 . This boundary occurs, I would propose, because stage 3 is appropriate to the problems of social control and conflict resolution in a simple society, whereas stage 4 contains assumptions more suitable for the model of a complex society.

Because stage 4 seems to be the first higher moral stage that is definitely not culturally universal, this paper focuses on the differences between stages 3 and 4 . Using interview data on subjects from both modernized and more traditional contexts in Kenya, the paper suggests how peoples' differing frames of reference are related to differing basic moral concepts. For the more modernized adults in this sample, the frame of reference is modern-day Kenya, the developing nation; for the more traditional adults, the frame of reference remains the local tribal community within Kenya. This distinction is shown to be empirically and theoretically related to use of stage 4 versus stage 3 moral reasoning. ${ }^{1}$

1. Abraham Edel (1968), a philosopher, has made a related suggestion that stages 5 and 6 may be culturally specific to constitutional democracies of the Western model. This hypothesis could be tested by interviewing adults from societies that are as complex as the Western industrial nations but are guided by different political and economic ideologies (e.g., the USSR or China) . Such a study would show whether the most sophisticated moral reasoning in the noncapitalist countries assumes the forms defined by Kohlberg as stages 5 and 6. In the absence of such evidence, this essay limits itself to the extended consideration of stages 3 and 4 and their relationships to social organization. 


\section{METHOD}

\section{SAMPLES}

Two samples are considered: first, a group of young men and women studying at the University of Nairobi; and second, a group of adults and secondary students from seven communities located in different parts of Kenya.

The university sample consists of 52 students ( 35 male, 17 female) whom I interviewed at the University of Nairobi. These students constitute an extremely heterogeneous sample in terms of ethnic group, age, family background, and major field of study at the university. The majority ( 35 subjects) were black Africans from all of the major tribes represented at the University of Nairobi, while the minority (17 subjects) were Asiatics of Indo-Pakistani descent. In general, the university subjects were slightly older than most United States college students since they ranged in age from 19 to 31 , with a median of 22.2. They came from large families (median number of siblings, 6.1) and the majority of their parents had had little formal education (median number of years of education for mothers, 4.0, for fathers, 6.0). Most of their fathers (29) were subsistence farmers or manual laborers; others (23) were white-collar workers. In one important respect the subjects are outstanding members of their age group in Kenya. All of them have proved extremely successful at academic work, since only a tiny minority of students who enter secondary school are able to pass through the stepwise sequence of qualifying examinations that admit students to the university system. The university subjects were recruited in classes and through personal contacts. Possible subjects were informed that the purpose of the study was to understand their ideas of right and wrong by having them discuss some hypothetical moral dilemmas. Each subject received seven shillings for the interview (one U.S. dollar).

The second sample consists of 47 males and 14 females living in seven communities in the Central and Western Provinces of Kenya. These subjects belonged to five different ethnic groups-four African tribal groups (the Kikuyus, Merus, Kipsigis, and Luyias) and one Asian, or Indo-Pakistani, religious sect (the Ismailis). This sample is termed the community sample because of the method of data collection. Seven University of Nairobi students (4 male, 3 female) served as the staff of interviewers. The students, upper level 
majors in the social sciences, had been trained in the technique of moral judgment interviewing but were not taught Kohlberg's theory of stages (in order that their interview translations and transcriptions would not be biased). During the December school holidays, each of the student interviewers returned home and conducted interviews with subjects of his or her own ethnic group. The interviewer selected as subjects secondary school students (also home for vacation) and adults residing in his or her local area. ${ }^{2}$ Although the goal for each interviewer was ten subjects, in most cases shortage of time prevented full completion of this plan. The final community sample consisted of 25 secondary school students and 36 adults.

The adult subjects were all community leaders, that is, men and women who might be considered "moral leaders" in their locales. Those chosen had reputations as responsible citizens-persons noted for giving useful advice and counsel. Most of these subjects were officers or members of local civic organizations and church groups; a few were also holders of local political office. Because the interviewers worked in a variety of communities (ranging from the rather traditional rural location of Sigor in Western Province to the modern capital city of Nairobi) the subjects whom interviewers selected as community leaders varied from nonschooled peasant farmers to college-educated school teachers. Approximately half of the subjects were farmers or unskilled laborers while the rest held white collar jobs (teaching, office work, business management). Ages ranged from 23 to 75 , with a median of 48 . Their median years of formal education were 8.5. Twenty-five of the community leaders were male, 11 were female.

The secondary school subjects chosen from the same communities serve mainly as a kind of comparison group to the community leaders. These 25 subjects simply offer a sampling of the moral thought and values of the "new generation" in the communities. They were students whose homes were near the interviewers; they

2. The seven communities in which students interviewed were: (1) Githiga location, 25 miles from Nairobi (a community of Kikuyu speakers); (2) Meru Mwimbi location, 40 miles from Meru (a community of Kimeru speakers);

(3) Sigor location, 50 miles from Kericho (a community of Kipsigis speakers);

(4) Idakho location, 12 miles from Kakamega, and (5) North Wanga location, 50 miles from Kisumu (both communities of Baluyia speakers); (6) Nairobi, and (7) Kisumu (two cities in which Ismailis were interviewed). 
were not selected on the basis of personal characteristics. Some attended prestige national boarding schools for top students from all over Kenya, while others attended schools in their local areas. They came from all six of the grades (or "forms") of secondary school, and they ranged in age from 17 to 27 , with a median of 19.6. Because it was much easier for the interviewers to locate male than female secondary school students, most of the subjects were male (21 out of 25 ).

\section{THE INTERVIEW}

The moral judgment interview included four hypothetical moral dilemmas and a standard set of probing questions. ${ }^{3}$ Three of the dilemmas were standard Kohlberg stories especially adapted for the Kenyan setting (dilemmas of Heinz and the Drug, Mercy Killing, and the Father-Son Agreement), while the fourth dilemma was constructed in Kenya. One of the dilemmas (the fourth) is presented in table 2 below.

TABLE 2

Hypothetical Moral Dilemma

\section{Daniel and the School Fees}

A man, Daniel, managed to complete his secondary school education (Form 4) on the basis of school fees given him by his brother. Afterwards he married and took his wife to live with his parents in the rural area, while he got a job in the city. Eight years later, when his first son was ready to go to primary school, his mother and father came to him and said, "Your brother who educated you has been in an accident and cannot work, so you must now begin to pay for the education of your brother's child." This child was the same age as his own son. The man, Daniel, did not have enough money to pay school fees for both his own son and his brother's child. His wife said he must put his own son first.

1. What should Daniel do in this situation? Should he put his son or his brother's child first? Why?

2. What obligation does he have to his brother who educated him?

3. What does he owe his son?

4. Should he obey his parents in this case? Do you think a grown son has to obey all of his parents' wishes? Why, or why not?

5. What should a grown son do for his parents?

6. Is it more important to maintain harmonious relations with his wife or with his brother and parents? Why?

7. Would you condemn Daniel if he just moved his wife and children to the city and did not pay for the education of his nephew? Why?

8. Would you yourself expect your eldest children to help their younger brothers and sisters with school fees? Why, or why not?

3. Thirty-one of the university subjects, as well as the entire community sample, were presented the full battery of stories 1 to 4 . The remaining 21 university subjects received only two or three of the dilemmas. Statistical com- 
Interviews of subjects with some secondary level education were conducted in English. Interviews of subjects with six or fewer years of schooling were conducted in native languages and later translated into English by the university students who conducted the interviews.

\section{SCORING AND RELIABILITY}

Interviews were taped and later transcribed. The global method (Kohlberg 1972) was followed for scoring. Each subject's full interview protocol was considered as a whole and assigned the stage code (stages 1 to 6) most representative of the overall level of the subject's moral reasoning. ${ }^{4}$ Many subjects, however, could not be classified at one single stage because in one or more of the dilemmas they presented clear evidence of $t w o$ adjacent stages, such as stages 2 and 3 (more than two adjacent stages were not seen in any subjects). These subjects were classified as intermediate and assigned a "mixed" score; for example, a 2(3) score ("major" stage of 2, "minor" stage of 3) indicated that the bulk of a subject's discussion lay at stage 2, with some secondary amount at stage 3 .

Forty interviews (20 university, 20 community) were independently scored a second time. The Spearman rank-order correlations between the two scorers indicated satisfactory reliability $\left(r_{B}=0.85\right.$ for the university subsample; $r_{s}=0.83$ for the community subsample). In addition, percentage agreement between the two judges attained the levels of $95 \%$ and $90 \%$, respectively, for the two samples (here agreement, following Haan, Smith, and Black [1968], has been defined as either agreement on the major stage designation or simple reversal of the major and minor stage designations).

parison of the latter group with the other university subjects, however, suggests that the variable number of dilemmas did not introduce systematic bias (either upward or downward) into the moral judgment coding.

4. To make these judgments, the Issue Scoring Manual (Kohlberg 1972) was used. This manual gives detailed descriptions of stages 1 to 6 modes of reasoning with respect to ten fundamental moral "issues" (such as property rights and punishment); these issues are defined or conceptualized in characteristically different ways at each moral judgment stage. Because all four moral dilemmas were designed to elicit ideas about the fundamental "issues," statements made by subjects could be compared with statements in the scoring manual. The scorer, reading a subject's interview, recognized stage-typical modes of thought and judged into which of the six moral judgment stages a subject's interview could best be placed. For example, the scorer classified as stage 1 a subject who displayed virtually nothing but stage 1 arguments throughout his interview. 


\section{RESULTS}

Table 3 presents the distribution of the moral judgment scores for the university and community subjects. Frequencies of subjects receiving each of the different stage assignments are given. The subjects with "intermediate" or "mixed" scores are included in the mixed categories (e.g., subjects who were intermediate between stages 2 and 3 are included in the category Mixed 2-3).

Table 3 shows that stage 4 reasoning is much more evident among the university subjects than the community leaders, although the leaders are on the average much older than the university students (and have therefore had more time to develop). Among the university students, $31 \%$ of subjects show major or minor stage usage of stage 4 reasoning. In contrast, among the community leaders, only $11 \%$ of subjects display any stage 4 reasoning.

In contrast, stage 3 reasoning is as frequent among the community leaders as among the university students. The two groups are quite similar with respect to stage 3 usage, and contrast with the secondary subjects, who show much more stage 2 (and mixed stage 2 ) reasoning. This higher percentage of stage 2 in the secondary sample is not unexpected given the young age of the sample. Thus, the community leaders are differentiated from the secondary students with respect to stage 2 usage (a finding probably owing to development with age) and are differentiated from the university subjects with respect to stage 4 usage (a finding certainly not owing to an age factor).

If age is not a relevant dimension with which to explain the stage 4 usage difference between the community leaders and university students, the question arises as to what could explain it. The critical variable certainly cannot be lack of concern with moral questions by the community leaders since all of them were noted "moral leaders" in their communities. There are at least two conspicuous differences, however, between the university students on the one hand and the community leaders on the other hand which might play a role in the stage 3 versus 4 dimension. The university students have undergone much more formal education and are oriented much more thoroughly toward professional jobs in the modern sector of the Kenyan economy than are most of the community leaders. That these might be critical variables receives strong support from the brief personal sketches presented below of the four community leaders who do show stage 4 reasoning: 


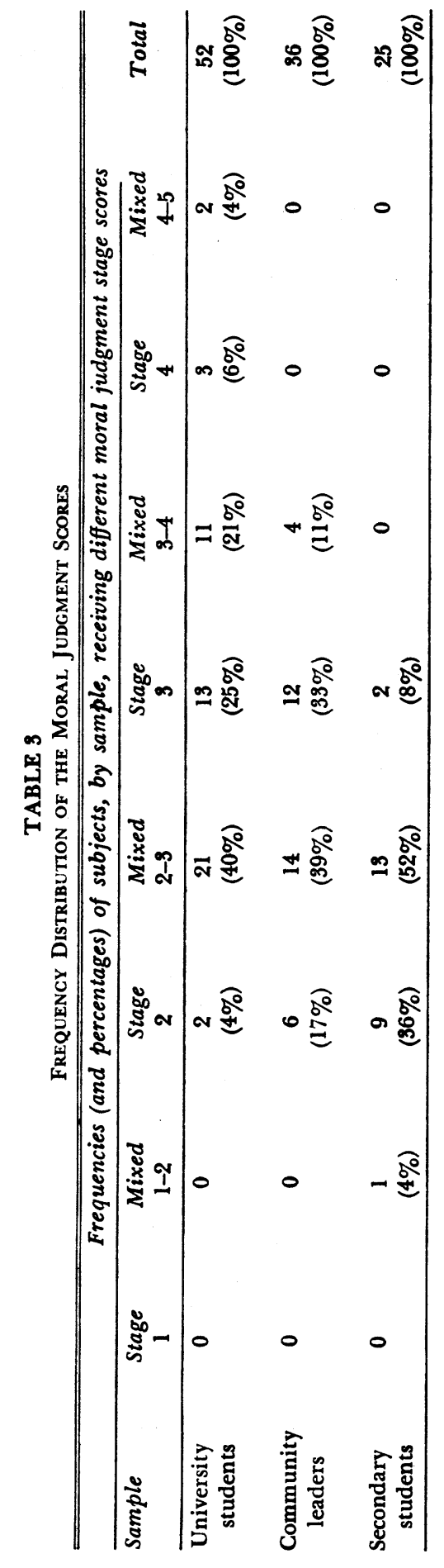


1. A Luyia man, aged 36 , who was teaching primary school in a rural area in the Western Province. He had attended 8 years of formal education (primary school only).

2. A Kimeru man, aged 27 , who at the time of the study was on leave from his job as bank officer. He had worked in several different provinces of Kenya in the towns of Kisii, Mombasa, Naivasha, and Nairobi. He had attended the renowned Alliance High School in Central Province for six years and then studied for one further year in London.

3. An Ismaili woman, aged 27 , who was working as a chartered secretary for a firm in Nairobi. She had attended four years of secondary school in Mombasa, Kenya, and then completed the final two years in England. She also had attended four years of secretarial college in England.

4. An Ismaili man, aged 26 , who owned a large business in the city of Kisumu in Western Province. He had attended four years of secondary school in Kisumu, then gone to Bath Technical Institute in England for four years altogether, where he obtained a bachelor's degree in business administration.

Notice that both men and women, and members of three of the five ethnic groups, are included in this small group. Such diversity suggests that neither sex nor ethnic group are the important variables underlying the stage 3-stage 4 distinction. Rather, the personal sketches suggest that either higher education, professional occupational roles, or both, are more important. Such a suggestion receives support from the pattern of scores for the full community leaders group with respect to both education and occupation versus moral stage score.

Table 4 presents the data for the full community leaders sample. The table displays the frequency of the moral stage scores with respect to subjects' level of education and type of occupation. Subjects were categorized as having "primary" level of education if they had attended one to eight years of primary school, they were categorized at the "secondary" level if they had attended one or more years of secondary school, and they were labeled "college" if they had attended some type of postsecondary institution (e.g., business college). The findings show that education and occupation relate positively to the moral judgment scores. Stage 4 reasuning is linked to college education and white collar occupation. 
TABLE 4

Distribution of Subjects within the Community leaders Sample, by Moral JUdGMENT SCORE Versus EduGation and Occupation

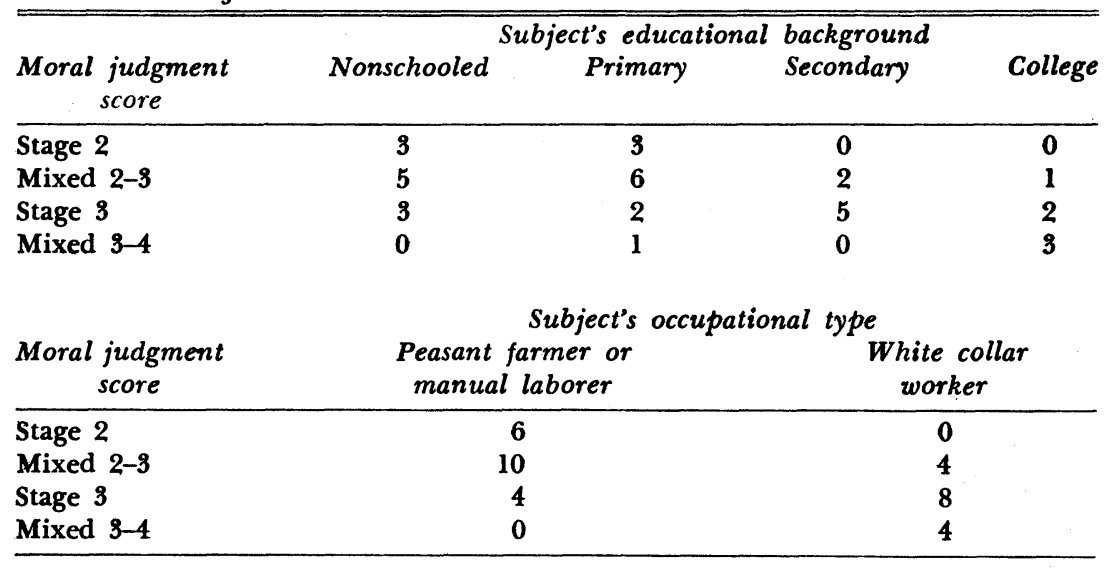

Of course, education and occupation should not be thought of as independent factors-they are highly intercorrelated in the sample. Some of the community leaders can be considered highly "modernized"- they attended Western-style schools for many years and they now occupy white collar jobs in the modern sector of the Kenyan economy. They either live in cities or serve as teachers for schools in the rural area. Others of the community leaders are much more "traditional" - they did not receive much, if any, Westernstyle schooling and they live in the rural areas where they either own farms or do manual work. This latter group of individuals, however, should not be thought of as people at the bottom of the Kenyan social hierarchy. Within their own village communities they are quite eminent; they may be wealthy by local standards and they certainly wield power and influence. Within their own frame of reference (what might be called the "traditional" sector of the Kenyan economy), they are "big men" and highly respected women.

\section{DISCUSSION}

The empirical findings suggest that stage 3 may be the highest of Kohlberg's moral judgment stages commonly found among "moral leaders" in Kenya whose frame of reference is the semitraditional, rural village community. Stage 3 may represent the mature moral perspective in this type of cultural setting, the face-to-face society. 
In contrast, stage 4 modes are more frequently expressed by the new elite (the university students) whose education and goals make their frame of reference modern-day Kenya, the developing nation.

The trend of these findings is supported by three other crosscultural studies of adult groups. Research in Turkey (Turiel, Kohlberg, and Edwards n.d.), Thailand (Batt 1974), and India (Parikh 1975) indicates that under the most recent rules of scoring, stage 3 is the highest of Kohlberg's stages found among traditionally oriented adults from peasant societies. All three studies show substantial amounts of stage 4 modes of reasoning among the universityeducated portions of their samples.

An explanation for all of these findings lies in the character of the stage 3 and 4 modes of reasoning. Built into the operational definitions of stages 3 and 4 are different assumptions about the nature of society. Stage 3 assumptions, I argue, correspond to the model of the face-to-face community, while those of stage 4 correspond to a state, or national, model. This can be demonstrated through an analysis that considers, on the one hand, some basic aspects of life in the two types of societies, and on the other hand, the ways in which stages 3 and 4 are differentiated from each other with respect to five basic moral "issues" or categories: (1) authority, (2) punishment, (3) rules and law, (4) guilt and blame, and (5) individual liberty. Other issues besides these five might have been included; but this sample serves to show how modes of moral judgment may reflect the conditions of life in different kinds of societies. Excerpts from the Issue Scoring Manual (Kohlberg 1972) illustrate how the different moral issues are defined at stages 3 and 4.

A face-to-face society, such as a tribal group, and a state or national system differ in their institutions and processes of social control. E. Adamson Hoebel (1954) discusses this problem with reference to primitive versus civilized law. Hoebel states, "the more civilized man becomes, the greater is man's need for law, and the more law he creates" (1954:293). Simply to perform the functions of maintaining public order and resolving civil disputes, a state system requires more elaborate and formal legal institutions than does a tribal society.

At the level of tribal society, most disputes or "trouble cases" can be settled with justice and dispatch by conference between the disputants, aided by respected clan or tribal elders who mediate the 
case (Gluckman 1955, Bohannan 1957, Gulliver 1963). The mediators judge according to cultural norms that represent a flexible set of guidelines rather than a formal body of laws. The mediators' job involves more than simply weighing the evidence and deciding in favor of one side of the dispute or the other. The mediators must give justice where justice is due and at the same time create a workable compromise that will be tolerated by both parties. They must take care to reestablish harmony in the community as well as uphold the moral norms (Snell 1954, Saltman 1971) since no central authority exists to enforce the mediators' decision.

A national state requires more formal and elaborate legal mechanisms because of those social control problems inherent in urbanization and the expansion of the social unit to a much larger scale (Hoebel 1954:327-329). In the first place, urbanization breaks down the organization based upon kinship and personal ties which is characteristic of tribal society. It thereby frees the individual from the control of his kinsmen and sets him among large groups of strangers. New mechanisms must be devised to take over the work of the kinship network. Allegiance to the state and the law must be forged out of loyalty and obedience to the clan. In the second place, when urban centers arise in multicultural societies, they function to bring together masses of people who have different backgrounds and also different values, goals, and life-styles. Value diversity proliferates in cities and brings with it a whole new series of social problems. Legal and moral conceptions must be developed to guide individuals in this complex situation. Both of these factors - the loss by the individual of the face-to-face community, and the heterogeneity of values encountered in the city-can be linked to the differences between stages 3 and 4 types of moral judgment.

Urbanization loosens the ties between the individual and his kinship group and shifts the responsibility for controlling him from the face-to-face community to the "state." The state is an impersonal and anonymous system as far as individuals are concerned. The authority of state officials over the individual rarely has any elements of a personal relationship, as it always does in a face-to-face community, where the seniority and the leadership qualities of authorities naturally inspire respect. The impersonality of the state, however, requires that other reasons be developed for obeying government officials. One possible reason is respect for the authority's 
office and for the system that underlies that office. Here is the distinction between the stage 3 and stage 4 ideas of respect for authority.

Stage 3. Respect for authority based on affection or belief in his personal virtue, his concern for subordinates, and what he has done in the past for them.

Stage 4. An internal attitude of respect for authority is expected based on the authority representing society and order.

(Kohlberg 1972: Tables Set A)

When the responsibility for controlling the individual shifts from the face-to-face community to the state, the sanctioning agents for wrongdoing change from being the people in the community to institutionalized legal authorities. This transition can be linked to differences between stages 3 and 4 concepts of punishment and of rules and laws. In the tribal setting, the problems created by interpersonal disputes bring local groups into conflict and threaten to tear the community apart (Hoebel 1954). Therefore, the task of the mediators of a trouble-case is to work out a solution that will restore good relations between the plaintiff and his supporters and the defendant and his supporters. For example, in traditional customary Kipsigis law, a homicide case was settled when the clan of the murderers paid blood money to the clan of the victim. If the killer had murdered several times and was considered incorrigible by his clan, he would be abandoned to the vengeance of the victim's relatives. For the national state system, the responsibility for punishing wrongdoers is vested not in the local community but in the state itself. Permanent institutions, in the form of police, courts, and prisons, exist to settle both the civil and criminal cases in the society. Hence it is a punishable offense for private groups to "take the law into their own hands" and seek their own vengeance. This distinction between tribal and state processes of conflict resolution is reflected in the stage 3 versus 4 concept of punishment:

Stage 3. The function of punishment is to reform the culprit, to strengthen his desire to be good, and to restore his relations to the victim by repayment and forgiveness. 
Stage 4. Punishment expresses the horror at the crime felt by lawabiding men, and is designed to teach that horror (or remorse) to the criminal. Crime is an offense against society, punishment is paying one's debt to society.

(Kohlberg 1972: Issue G)

Further, in the tribal setting, the rules that the mediators use to resolve disputes are flexible guidelines or norms that define duty and obligation for the social roles of the group. In contrast, for the state there is a fixed uniform code of law to give order across all of the disparate local regions within the society. This contrast is seen in the stage 3 versus stage 4 concept of rules and laws.

Stage 3. Rules and laws are guides ... to social or "good end seeking." They are guides to "being good."

Stage 4. Rules and laws are a fixed system of general rules to be followed always, a system designed to prevent social disorder and chaos. Rules and laws define "right and wrong" categorically.

(Kohlberg 1972: Tables Set A)

A second feature of the state as opposed to the tribal society is the extreme heterogeneity of values of its citizens. As is clearly seen in Kenya today, urbanization throws together masses of people from different cultural backgrounds who disagree with each other on major as well as minor issues of morality. In a face-to-face community, where people tend to share many basic standards, it is reasonable to view wrongdoing as displeasing "the community." The moral individual does not want to offend the people among whom he has always lived and whose opinion he esteems. In the urban setting, however, standards are not even approximately shared and doing wrong cannot simply be a matter of offending "people's ideas." Instead, the moral individual might orient toward the imagined disapproval of people whose values he does accept. This audience could be somewhat abstract in constituency, as when a scientist thinks about "the community of science." Such a contrast is embodied in the distinction between the stage 3 and 4 conceptions of guilt and blame. 
Stage 3. Oriented to disapproval by others. This disapproval shades over into guilt in the sense that ... [imagined disapproval may be] . . . motivating, even if it is [actually] possible to avoid detection. Concern about disapproval from authority or victim as reason for moral conformity ... depends for its potency upon a personal relationship to the person disapproving.

Stage 4. A concern for loss of respect by one's peers or by disinterested members of the community; [this concern] is more or less identical with a loss of self-respect. Concern about other's respect is based on the fact that standards are shared with others. ... Respect is different from approval in being an impersonal judgment according to standards shared by the self. The validity of the respect of others rests upon its being based on standards shared or accepted by the self, and used by the self in judging others.

(Kohlberg 1972: Issue B)

The extreme heterogeneity of values in the urban setting can be traced to other ideas of morality besides guilt and blame. It also has links to ideas about rights of the individual. In the context of pervasive value divergence, individuals must be provided some reasonable amount of freedom from interference by others who dislike their religion, political views, life-styles, and so on. Society must define what is such a reasonable amount of freedom and then protect it through law. The domain of protected freedom can be called the "rights of the individual." The issue of protecting personal liberty arises in a different way in a small community where people share certain general standards about good and bad conduct. For example, in a tribal society, people often disagree with each other but this occurs against the background of a certain minimal level of agreement about moral standards. Values about personal liberty, however, may still be important for a tribal society. People may be expected to grant each other enough autonomy to live their lives in peace. This value would be expressed in terms of refraining from malicious gossip and minding one's own business, not respecting people's "natural or human rights." Of course, personal liberty would not be considered to be unlimited. Sometimes it would be considered proper to intrude upon other's privacy-for example, when someone is secretly engaged in immoral conduct. The distinction just elaborated between individual rights in the national 
context versus reasonable liberty in the tribal setting, appears in the stage 3 versus 4 concept of liberty and civil rights.

Stage 3. Issues of rights and liberty are subordinated to "nice" or humane treatment of one person by another. One can infringe on the liberties of others for a prosocial purpose, and one's own liberties are restricted by the requirement that one be prosocial.

Stage 4. Liberties are one of a class of rights deriving from society or guaranteed by society. These rights are "absolute" with regard to the whim or demands of another individual, but they are defined by society and may be restricted for the sake of social order and welfare.

(Kohlberg 1972: Tables Set A)

\section{CONCLUSION}

The discussion has suggested why different modes of moral decision-making are appropriate for the tribal versus national frames of reference. In terms of Kohlberg's stage system of moral judgment, stage 3 is the type of thinking most suitable for a faceto-face community, while stage 4 is more suitable for the national state. Although stage 4 is considered more complex and differentiated than stage 3 , it is not as a function of its greater cognitive difficulty that it is more likely to be absent among peasant villagers than urban dwellers. Rather, stage 4 incorporates notions of authority, punishment, rules and law, guilt and blame, and individual liberty which are directly relevant to conditions of life in the urban context. An urban existence-with its anonymity, impersonality, and heterogeneity-presents moral problems that are not met in the face-to-face community. New mechanisms of social control are developed in the transition from tribal to civilized society, and new modes of moral judging may evolve as a result of the same social forces. Modes of moral judgment should be viewed as adaptive structures developed by people to accomplish important cognitive tasks at hand. They should not be seen as "achievements" for which "higher" is necessarily better. Insofar as we come to understand what are the cognitive requirements of life in different kinds of social environments, we will learn along what dimensions the processes of thought may differ from culture to culture, or even from subculture to subculture within a pluralistic society such as our own. 


\section{REFERENCES}

Aronfreed, Justin. 1968. Conduct and Conscience: The Socialization of Internalized Control over Behavior. Academic Press.

Baldwin, James Mark. 1902. Social and Ethical Interpretations in Mental Development. The Macmillan Company.

BatT, H. William .1974. Guilt, Shame, and the Bureaucratic Model: With Specific Reference to Thai Public Administration. Ph.D. dissertation, Department of Political Science, State University of New York, Albany.

Bohannan, Paul. 1957. Justice and Judgment among the Tiv. Oxford University Press.

Bruner, Jerome S., Rose R. Olver, and Patricia M. Greenfield. 1966. Studies in Cognitive Growth. John Wiley and Sons, Inc.

Cole, Michael, John Gay, Joseph A. Glick, and Donald W. Sharp. 1971. The Cultural Context of Learning and Thinking. Basic Books, Inc.

Dewey, John, and James H. Tufts. 1908. Ethics. Henry Holt and Company.

Edel, Abraham. 1968. Scientific Research and Moral Judgment. Paper delivered at the Conference on the Acquisition and Development of Values, National Institute of Child Health and Human Development.

Gladwin, Thomas. 1970. East is a Big Bird. Harvard University Press. Gluckman, Max. 1955. The Ideas in Barotse Jurisprudence. Yale University Press.

Gorsuch, Richard L., and M. Louise Barnes. 1973. Stages of Ethical Reasoning and Moral Norms of Carib Youths, Journal of CrossCultural Psychology 4:283-301.

Gulliver, Philip H. 1963. Social Control in an African Society. Routledge and Kegan Paul .

HAAN, N., M. B. SMITh, and J. BLock. 1968. The Moral Reasoning of Young Adults: Political-Social Behavior, Family Background, and Personality Correlation. Journal of Personality and Social Psychology 10:183-201.

Hовноuse, L. T. 1906. Morals in Evolution: A Study in Comparative Ethics. Chapman and Hall, Ltd.

Hoebel, E. Adamson. 1954. The Law of Primitive Man. Harvard University Press.

Horton, Robin. 1967. African Traditional Thought and Western Science. Africa (pt. 1) 37:50-71; (pt. 2) 37:155-187.

Kant, Immanuel. 1887. The Philosophy of Law, trans. by W. Hastie. T. and T. Clark. 
Kohlberg, Lawrence. 1963. Moral Development and Identification, Yearbook of the National Society for the Study of Education $(\mathrm{H} . \mathrm{W}$. Stevenson, ed.), pp. 277-332. Part I, Child Psychology. University of Chicago Press.

- 1969. Stage and Sequence: The Cognitive-Developmental Approach to Socialization, Handbook of Socialization (D. Goslin, ed.), pp. 347-480. Rand McNally.

- 1971. From Is to Ought, Cognitive Development and Epistemology (T. Mischel, ed.), pp. 151-235. Academic Press.

- 1972. Issue Scoring Manual. Moral Education Research Foundation.

Kohlberg, Lawrence, Kelsey Kauffman, Peter Scharf, and Joseph Hickey. 1974. The Just Community Approach to Corrections: A Manual, Part II. Moral Education Research Foundation.

Mead, George Herbert. 1934. Mind, Self, and Society. University of Chicago Press.

Parikh, Bindu. 1975. Moral Judgment and Development and Its Relation to Family Environmental Factors in Indian and American Urban Upper-Middle Class Families. Ed.D. dissertation, Department of Special Education, Boston University.

Piaget, Jean. 1932. The Moral Judgment of the Child. Routledge and Kegan Paul.

Saltman, Michael. 1971. A Restatement of Kipsigis Customary Law. Ph.D. dissertation, Department of Anthropology, Brandeis University.

Simpson, Anna Louise, and Douglas Graham. n.d. The Development of Moral Judgment, Emotion, and Behavior in British Adolescents, Moralization: The Cognitive-Developmental Approach (L. Kohlberg, ed.), Holt. Rinehart and Winston (forthcoming).

SNeLL, G. S. 1954. Nandi Customary Law. Macmillan and Company, Ltd.

Spencer, Herbert. 1899. The Principles of Ethics, Volume I. D. Appleton and Company.

Turiel, Elliot, Lawrence Kohlberg, and Carolyn P. Edwards. n.d. A Cross-Cultural Study of Moral Development in Turkey and the United States, The Structure of Change in Cognitive and Social Development (E. Turiel and J. Langer, eds.) (forthcoming).

White, Charles B. 1975. Moral Development in Bahamian School Children: A Cross-Cultural Examination of Kohlberg's Stages of Moral Reasoning. Developmental Psychology 11:535-536. 